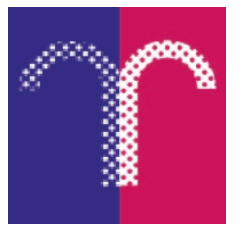

\title{
RESPIRATORY RESEARCH
}
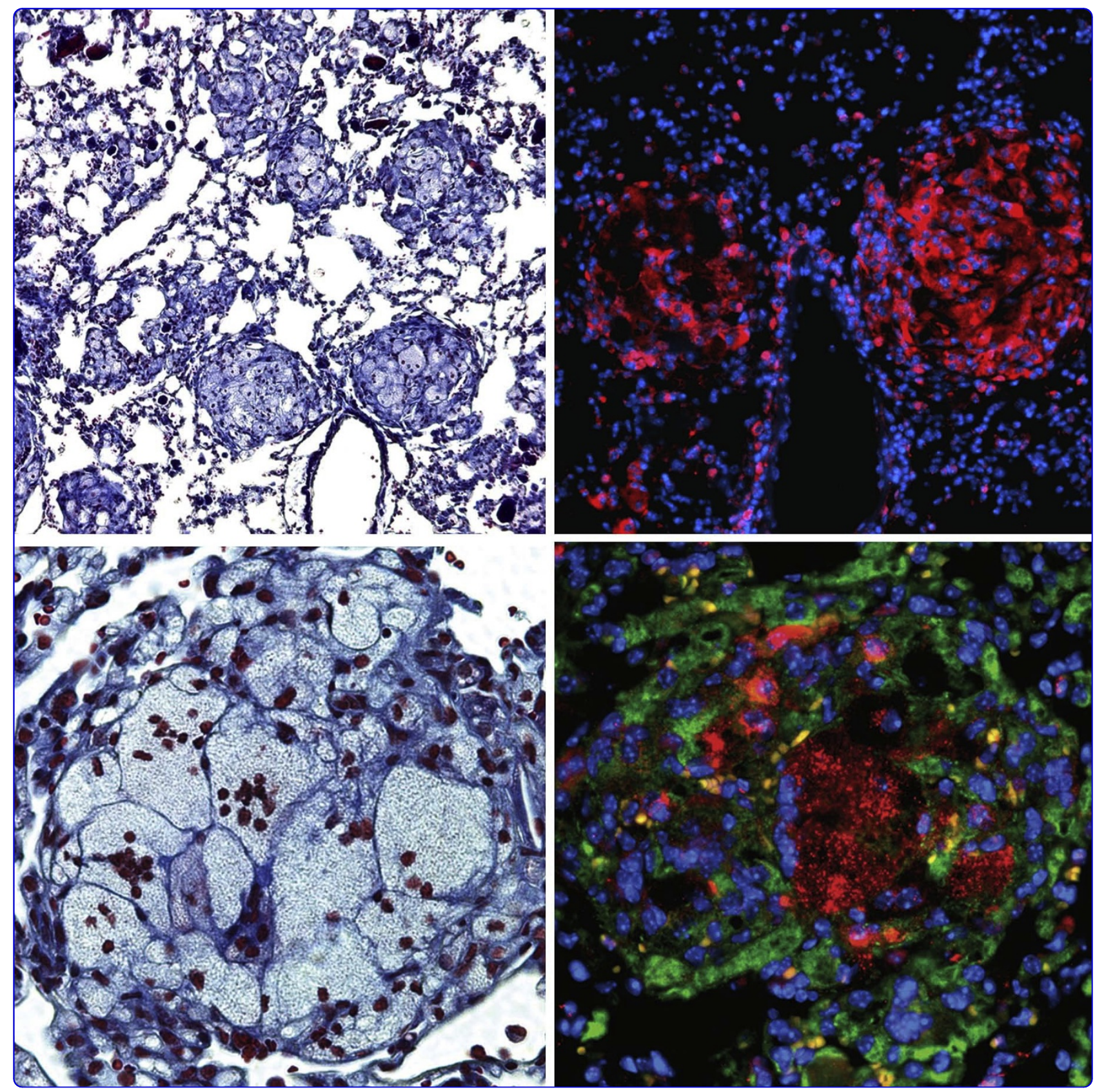

\section{Lack of cathepsin activities alter or prevent the development of lung granulomas in a mouse model of sarcoidosis}

Samokhin et al. 


\title{
Lack of cathepsin activities alter or prevent the development of lung granulomas in a mouse model of sarcoidosis
}

\author{
Andriy O Samokhin ${ }^{1}$, Jacques Yves Gauthier², M David Percival², Dieter Brömme ${ }^{\text {** }}$
}

\begin{abstract}
Background: Remodeling of lung tissues during the process of granuloma formation requires significant restructuring of the extra-cellular matrix and cathepsins $K, L$ and $S$ are among the strongest extra-cellular matrix degrading enzymes. Cathepsin $\mathrm{K}$ is highly expressed in various pathological granulomatous infiltrates and all three enzymes in their active form are detected in bronchoalveolar lavage fluids from patients with sarcoidosis. Granulomatous inflammation is driven by T-cell response and cathepsins $S$ and $L$ are actively involved in the regulation of antigen presentation and T-cell selection. Here, we show that the disruption of the activities of cathepsins $\mathrm{K}, \mathrm{L}$, or $\mathrm{S}$ affects the development of lung granulomas in a mouse model of sarcoidosis.

Methods: Apolipoprotein E-deficient mice lacking cathepsin $K$ or $L$ were fed Paigen diet for 16 weeks and lungs were analyzed and compared with their cathepsin-expressing littermates. The role of cathepsin $\mathrm{S}$ in the development of granulomas was evaluated using mice treated for 8 weeks with a potent and selective cathepsin $\mathbf{S}$ inhibitor.

Results: When compared to wild-type litters, more cathepsin K-deficient mice had lung granulomas, but individually affected mice developed smaller granulomas that were present in lower numbers. The absence of cathepsin $\mathrm{K}$ increased the number of multinucleated giant cells and the collagen content in granulomas. Cathepsin $L$ deficiency resulted in decreased size and number of lung granulomas. Apoe-/- mice treated with a selective cathepsin S inhibitor did not develop lung granulomas and only individual epithelioid cells were observed.

Conclusions: Cathepsin K deficiency affected mostly the occurrence and composition of lung granulomas, whereas cathepsin $L$ deficiency significantly reduced their number and cathepsin $S$ inhibition prevented the formation of granulomas.
\end{abstract}

\section{Background}

Cathepsins K, L and S are members of the papain family of cysteine proteases that have been recently implicated in the development of various lung diseases [1]. It is believed that cathepsins participate in lung tissue remodeling based on their ability to degrade extra-cellular matrix, their involvement in the regulation of immune responses and their potential contribution to the kallikrein-kinin system [2-5]. In this study, we investigated the roles of cathepsins $\mathrm{K}, \mathrm{L}$, and $\mathrm{S}$ in the development of granulomas in mouse lungs that have features of human granulomas of

\footnotetext{
* Correspondence: dbromme@interchange.ubc.ca

'Department of Oral Biological and Medical Sciences, Faculty of Dentistry,

University of British Columbia, Vancouver, BC, Canada

Full list of author information is available at the end of the article
}

sarcoidosis [6]. Sarcoidosis is a systemic disease characterized by the presence of noncaseating epithelioid granulomas with a pulmonary involvement in $\sim 90 \%$ of the patients $[7,8]$. Cathepsins K, L, and $\mathrm{S}$ are expressed by lung macrophages, fibroblasts, and epithelial cells [9]. Significant expression of cathepsin K was first found in granulomas induced by Echinococcus granulosus in bovine lung [10]. A strong expression of cathepsin $\mathrm{K}$ was also observed in epithelioid and multinucleated giant cells (MGCs) in patients with sarcoidosis and tuberculosis $[11,12]$. The presence of active forms of cathepsins K, L and $\mathrm{S}$ was found in bronchoalveolar lavage fluids from patients with sarcoidosis [13]. Recently, we described that Apoe-/- mice fed a cholate-containing high fat diet develop lung granulomas that have many features of human

\section{Biomed Central}


granulomas of sarcoidosis [6]. Epithelioid and MGCs in such granulomas have shown strong immunostaining for cathepsin $\mathrm{K}$ suggesting that this protease might be involved in granuloma formation or resorption (6).

Similarly to cathepsin K, cathepsins L and S are able to degrade major extracellular proteins [14] but they are also involved in immune responses $[15,16]$. Since cathepsins $L$ and $S$ play significant role in antigen presentation and $T$ cell selection $[15,17]$ and the formation of granulomas has been linked to $\mathrm{T}$ cell activation [18-21], the disruption of cathepsins $\mathrm{L}$ and $\mathrm{S}$ activities might affect the development of granulomas.

Thus, based on the strong expression of cathepsin $\mathrm{K}$ in granulomas and the pivotal role of cathepsins $\mathrm{S}$ and $\mathrm{L}$ in the antigen presentation and $\mathrm{T}$-cell selection, we hypothesized that the disruption of these protease activities might interfere with lung granuloma formation. In this study, we investigated the effect of cathepsin $\mathrm{K}$ and $\mathrm{L}$ deficiencies and cathepsin $\mathrm{S}$ inhibition on the development of lung granulomas in Apoe-/- mice on Paigen diet.

\section{Methods}

\section{Animals}

Three groups of mice were used: apolipoprotein E-deficient (Apoe-/-) mice (Jackson Laboratories), double knockout mice lacking apolipoprotein $\mathrm{E}$ and cathepsin $\mathrm{K}$ (Apoe-/-Ctsk-/-) ( $\mathrm{n}=10)$ and double knockout mice lacking apolipoprotein $\mathrm{E}$ and cathepsin L (Apoe-/Ctsl-/-) (n = 19). Double knockout Apoe-/-Ctsk-/- and Apoe-/-Ctsl-/- mice were generated by crossing Apoe-/with the Ctsk-/- or Ctsl-/- mice as previously described [22]. Ctsk-/- and Ctsl-/- mice were kindly provided by Drs. P. Saftig (University of Kiel, Germany) and C. Peters (University of Freiburg, Germany). The single cathepsin deficiencies have the following phenotypes: Cathepsin K-deficient mice show an osteopetrotic phenotype with excessive trabeculation of the bone-marrow space [23] and increased fibrosis in lungs after treatment with bleomycin [24]. Cathepsin L-deficient mice deficient mice develop periodic hair loss and epidermal hyperplasia [25].

The following primer sequences were used for ApoE: 5"-GCCTAGCCGAGGGAGAGCCG-3"; 5"-TGTGAC TTGGGAGCTCTGCAGC-3"; 5"-GCCGCCCCGACTGCATCT-3"; for cathepsin K: 5"-GCCACACCCACACC CTAGAAG-3"; 5"-ACA AGT GTA CAT TCC CGT ACC-3"; and for cathepsin L: 5"-GGAGGGAGAGCGATATGGG-3"; 5"-TTCCTCATTGGTCTT-CCG-3"; 5"CGGAGAACCTGCGTGCAATCC-3". At 6 weeks of age mice were switched from normal to Paigen fat diet (HFD) which contained $18 \%$ fat, $1 \%$ cholesterol and $0.5 \%$ cholate; Test diet 57W4; Purina Mills. LLC, St. Louis, MO). After 16 weeks on HFD, mice were euthanized after overnight fasting by exsanguination under xylazine- ketamine anesthesia. Another two groups of Apoe-/mice were studied after 8 weeks on HFD, one group received high fat diet alone $(\mathrm{n}=12)$ and another received the same diet plus $0.01 \% \mathrm{w} / \mathrm{w}$ cathepsin $\mathrm{S}$ inhibitor $(\mathrm{n}=$ 12). The medicated diet was formulated by mixing the chow in meal form with finely dispersed crystalline, orally-active inhibitor to obtain a uniform distribution. The cathepsin S inhibitor (cpd 6 in [26]) was dosed as the sulfoxide prodrug (cpd 7 (Figure 1) in [26]) which is rapidly converted into the active sulfone inhibitor in vivo. The mice consumed approximately $4 \mathrm{~g}$ food per day with no difference in food intake or body weight increase (average final body weight $23.7 \mathrm{~g}$ males, $20.0 \mathrm{~g}$ females) between the two groups. Control Apoe-/- mice used for $\mathrm{CD}^{+}{ }^{+}$cell quantification in lungs were on normal diet for 22 weeks. Single cathepsin K and L null mice on high fat diet were not evaluated as previous experiments revealed that the induction of lung granuloma formation by high fat diet was dependent on the apolipoprotein $\mathrm{E}$ deficiency [6]. All animal procedures were approved by the Canadian Council on Animal Care.

\section{Tissue preparation}

After perfusion with ice-cold phosphate-buffered saline (PBS), lungs and thymuses were fixed in $10 \%$ buffered formalin for 5 hours at $4^{\circ} \mathrm{C}$, embedded in paraffin, and $5 \mu \mathrm{m}$ sections were cut and mounted onto Superfrost/ Plus slides (Fisher-Scientific, Ottawa, ON).

\section{Immunohistochemistry}

Sections were dewaxed, rehydrated, blocked with $10 \%$ goat serum in PBS, and incubated overnight at $4^{\circ} \mathrm{C}$ with the primary antibody in 1\% BSA in PBS: affinity purified rabbit polyclonal anti-cathepsin K (1: 50) [27], mouse monoclonal antibody against SMC $\alpha$-actin (1:100, Biomeda, Foster City, CA), rat anti-mouse Mac-3 antibody (1:100, Pharmingen, San Diego, CA), rabbit polyclonal anti-mouse osteopontin (1:100, ARP, Belmont, MA), rabbit polyclonal anti-CD4 (1:100, Abbiotec, San Diego, CA), rabbit polyclonal anti-CD8 (1:100, ANASPEC, San Jose, CA) or goat polyclonal anti-cathepsin $\mathrm{S}$ and anticathepsin L (Santa Cruz Biotechnology, Inc., Santa Cruz, CA). Sections stained for cathepsins S and L were blocked with $10 \%$ donkey serum in PBS. As negative

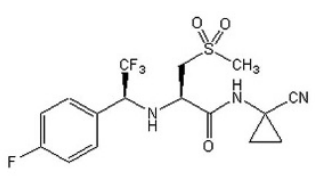

Figure 1 Structure of the cathepsin S inhibitor. Nitrile-based cathepsin $\mathrm{S}$ inhibitor (compound 7 according to [26]). 
controls, we used mouse, rabbit, rat or goat IgG at the same concentrations as the corresponding primary antibodies and for cathepsin $\mathrm{K}$ and $\mathrm{L}$ antibodies tissue sections from cathepsin $\mathrm{K}$ - and L-deficient mice were used. Tissue sections were then incubated with the appropriate secondary antibody: goat anti-rabbit Cy3conjugated, goat anti-mouse Cy2-conjugated antibody (1:200, Rockland, Gilbertsville, PA), goat anti-rat FITCconjugated antibody (1:200, Sigma-Aldrich, St. Louis, MO), and donkey anti-goat Texas Red-conjugated (1:200 v/v, Jackson ImmunoResearch Laboratories, West Grove, PA).

\section{Gomori's trichrome staining}

Sections were deparaffinized, hydrated with a graded alcohol series and distilled water, and placed in preheated Bouin's solution at $58^{\circ} \mathrm{C}$ for $10 \mathrm{~min}$. Sections were stained in Weigert's iron hematoxylin solution for 5 min, washed under running water for $30 \mathrm{sec}$, stained with Gomori's trichrome solution (Sigma-Aldrich, St. Louis, MO) for $15 \mathrm{~min}$, placed in $0.5 \%$ acetic acid for $10 \mathrm{sec}$, and then mounted for light microscopy.

\section{Morphometry, collagen content, and cell composition of granulomas}

The areas of granulomas stained positively for Mac-3, osteopontin, CD4 and CD8, and collagen were quantified using color threshold and calculated as percentage of granuloma area. The size of granulomas was measured in $\mathrm{mm}^{2}$. Trichrome stained sections were used for the measurement of granuloma size and for the quantification of collagen content. Images were captured with a Leica DMI 6000B microscope (Leica Microsystems, Inc, Richmond Hill, ON) and analyzed with Openlab 3 software.

\section{Quantification of the number of granulomas,} multinucleated giant cells and CD4-positive cells Five sections $200 \mu \mathrm{m}$ apart from each other were analyzed for each lung. For CD4-positive cell quantification three pictures per lung section were taken using a 40fold magnification, avoiding areas with dominating tracheal or bronchial tissue. The average number of granulomas and multinucleated giant cells per section and the average number of CD4-positive cells per captured area for each mouse were used for statistical analyses.

\section{Statistical analysis}

Student's t-tests were performed when values past test for normal distribution. Data are presented as mean \pm standard deviation. Discontinuous data (such as the number of granulomas) were analyzed using the MannWhitney U-test. Significance was concluded when $\mathrm{P}<0.05$.

\section{Results}

Cathepsins $\mathrm{K}, \mathrm{L}$ and $\mathrm{S}$ are expressed in mouse lung granulomas

Recently, we described that Apoe-/- mice receiving HFD develop epithelioid lung granulomas with characteristic features of granulomas of sarcoidosis [6]. Granulomas were composed of epithelioid cells, macrophages and $\mathrm{T}$ cells, and some granulomas also contained fibroblasts and multinucleated giant cells (MGCs) [6]. Figure 2A displays the typical phenotype of granulomas seen in this model. Similarly to granulomas of sarcoidosis, mouse lung granulomas were intensively stained for cathepsin $\mathrm{K}$ with the highest immunoreactivity in epithelioid cells forming the core of the granulomas (Figure 2B). Analysis of consecutive sections stained for cathepsins $\mathrm{L}$ and $\mathrm{S}$ revealed that similarly to cathepsin $\mathrm{K}$, cathepsin L was prevalently observed in the core of granulomas, whereas cathepsin S staining was weaker and uniformly distributed throughout the lung tissue (Figure 2C, D).

\section{Cathepsin K deficiency increased the incidence of granulomatous infiltrations in lungs}

Similarly to Apoe-/- mice, Apoe-/-Ctsk-/- mice receiving HFD showed fibrotic changes in lung tissues and the presence of such inclusions as Schaumann's bodies and crystalline structures (Figure 3A), which are nonspecific but are often present in patients with sarcoidosis. Apoe-/-Ctsk-/- mice also developed inducible bronchusassociated lymphoid tissues (iBALT) which are usually induced by inflammatory reactions and are present in

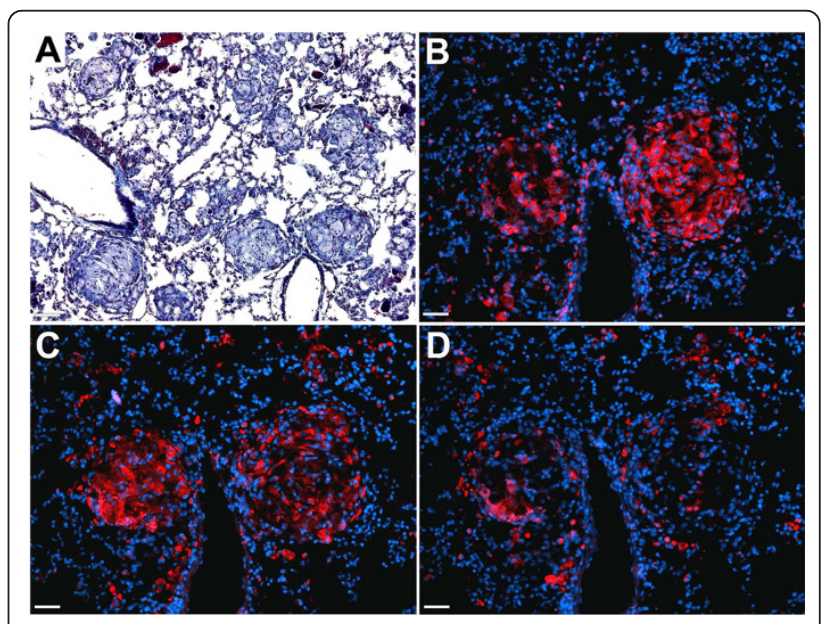

Figure 2 Expression of cathepsins in lung granulomas Cathepsins $\mathrm{K}, \mathrm{L}$ and $\mathrm{S}$ are expressed in lung granulomas of Apoe-/mice. (A), trichrome stained section shows well-formed lung granulomas. (B), cathepsin K immunostaining (red - cathepsin K, blue - nuclei). (C), cathepsin L immunostaining (red - cathepsin L, blue - nuclei). (D), cathepsin S immunostaining (red - cathepsin S, blue - nuclei). (A), scale bar $130 \mu \mathrm{m}$, (B-D), scale bars $65 \mu \mathrm{m}$. 


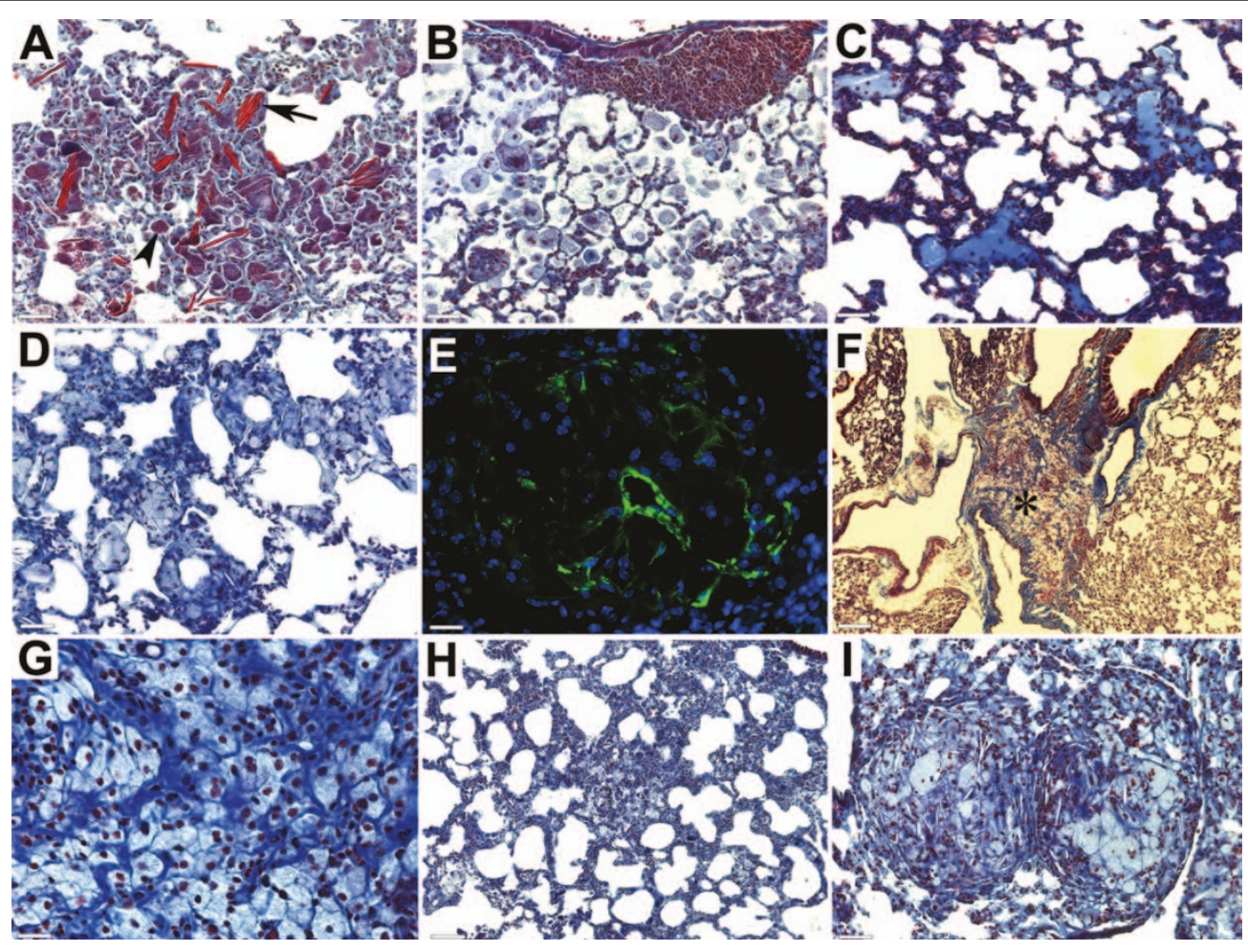

Figure 3 Structural changes in lungs of Apoe-/-Ctsk-/- mice. (A), extensive fibrosis with Schaumann's bodies (arrowhead) and crystalline structures (arrow). (B), inducible bronchus-associated lymphoid tissues (iBALT) and alveolar monocyte/neutrophilic infiltration. (C), proteinosis. (D), ring-like structures formed by epithelioid cells. (E), smooth muscle cell $\alpha$-actin positive cells in granulomas (green - smooth muscle cell $\alpha$-actin, blue - nuclei). (F), accumulation of epithelioid cells between layers of collagen fibers (* shows area magnified on $G$ ). (H), individual epithelioid cells in fibrotic areas with honeycombing appearance. (I), two granulomas with relatively large size. (A-D, F-I), trichrome stained sections. (A-E and I), scale bars $65 \mu \mathrm{m}$; (F), scale bar $260 \mu \mathrm{m}$; (G), scale bar $30 \mu \mathrm{m}$; (H), scale bar $130 \mu \mathrm{m}$.

bronchovascular bundles [28] (Figure 3B). Evidences of acute lung injury, such as alveolar monocyte/neutrophil infiltration and proteinosis, were also observed (Figure 3B and 3C). In Apoe-/- mice, $41 \%$ of the animals displayed lung granulomas, whereas in their cathepsin K-deficient littermates this number reached $88 \%$ (table 1). Notable differences in the morphology of granulomatous infiltrations were also observed. In some lung areas, the presence of epithelioid cells did not result in the development of well-formed and ball-shaped granulomas that were predominant in cathepsin K-expressing mice. In cathepsin K-knockout mice, epithelioid cells

Table 1 Percentage of mice with granulomas, proteinosis or IBALT in lungs

\begin{tabular}{lccccc}
\hline & $\begin{array}{c}\text { Apoe-/- } \\
(\mathbf{1 6} \text { w) }\end{array}$ & $\begin{array}{c}\text { Apoe-/- } \\
\text { Ctsk-/- } \\
(\mathbf{1 6} \mathbf{w})\end{array}$ & $\begin{array}{c}\text { Apoe-/- } \\
\text { Ctsl-/- } \\
(\mathbf{1 6} \mathbf{w})\end{array}$ & $\begin{array}{c}\text { Apoe-/- } \\
\mathbf{( 8} \mathbf{w})\end{array}$ & $\begin{array}{c}\text { Apoe-/- } \\
(\text { cat S inh) } \\
\mathbf{( 8 ~} \mathbf{~ w )}\end{array}$ \\
\hline Granulomas & 41 & 88 & 31 & 41 & - \\
Proteinosis & 17 & 11 & 26 & 9 & 8 \\
iBALT & 47 & 77 & 31 & 36 & 15 \\
\hline
\end{tabular}

were often organized in amorphous or ring-like structures formed by epithelioid cells (Figure 3D) and granulomas often contained an accumulation of fibroblast-like shaped cells showing positive staining for $\alpha$-actin (Figure 3E). In some lung areas, extensive accumulation of collagen fibers and epithelioid cells covered large areas between airways and blood vessels (Figure 3F, G). In more fibrotic areas that had honeycombing appearance, individual epithelioid cells were randomly dispersed (Figure $3 \mathrm{H}$ ). The average size of granulomas was significantly smaller in cathepsin K-deficient mice (see below) when compared to cathepsin K-expressing littermates, but some granulomas reached comparatively large sizes (Figure 2I) that might be related to changes in granuloma development in the absence of cathepsin $\mathrm{K}$.

Analysis of lung granuloma composition revealed that cathepsin K-deficient mice contained significantly higher number of MGCs per lung section (Figure 4A-C). Granulomas contained foreign body-type MGCs, with random distribution of nuclei (Figure 4A) and Langhans-type MGCs with horseshoe-like arrangements of nuclei (Figure 4B). Epithelioid cells and MGCs were intensively 

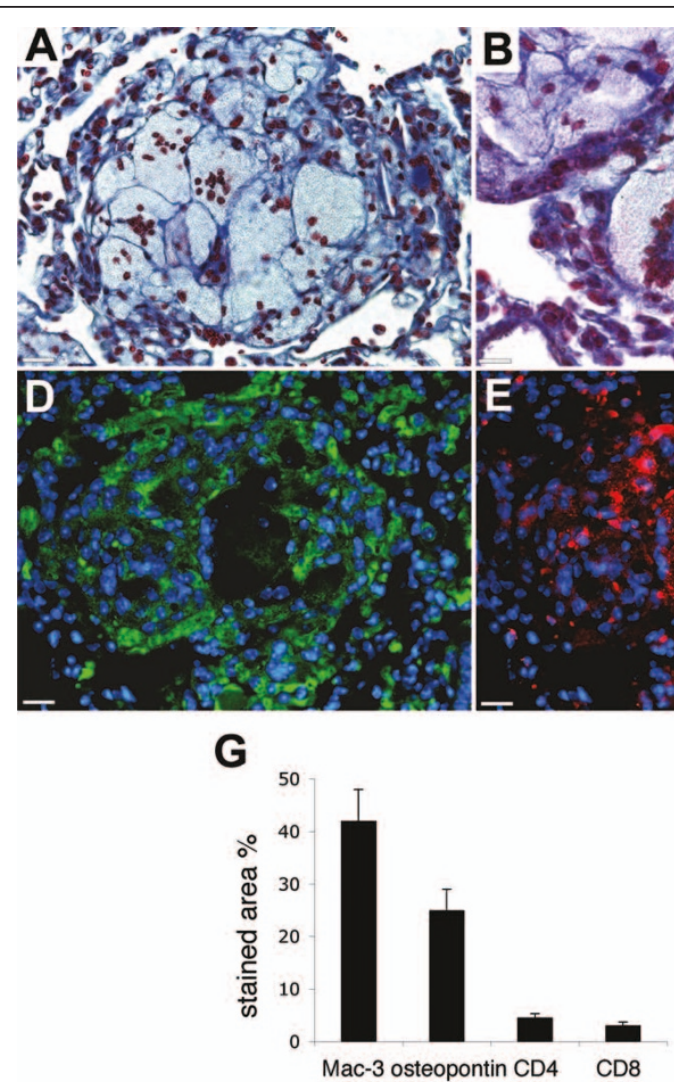
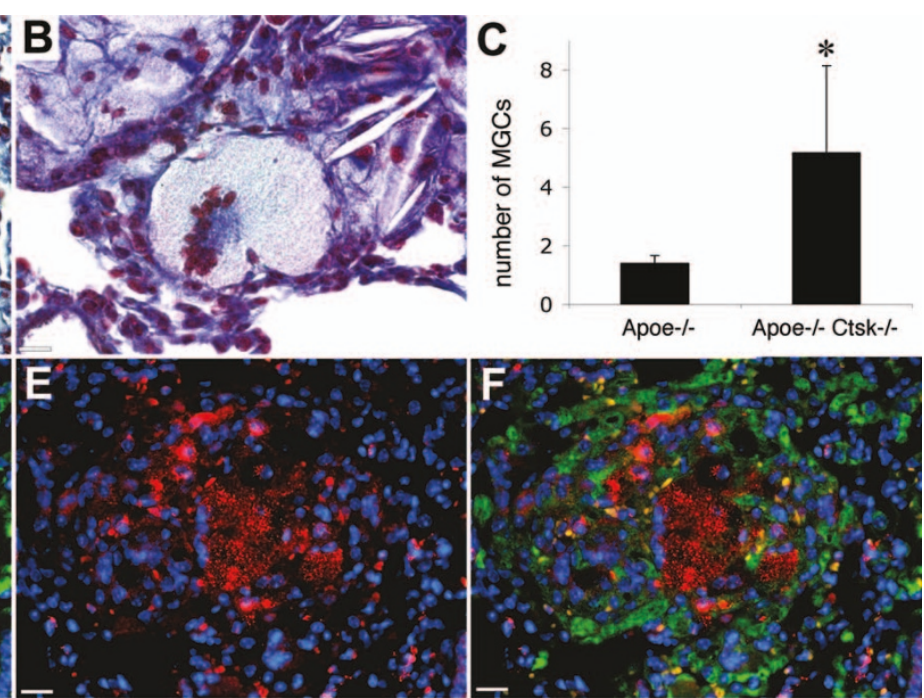

H

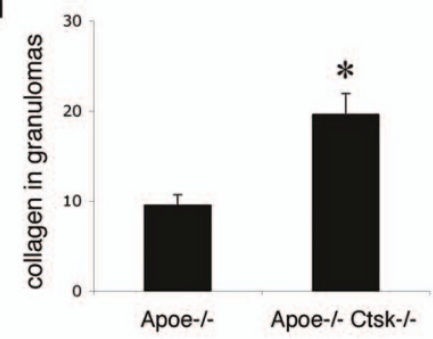

Figure 4 Granuloma composition in cathepsin K-deficient mice. (A), granuloma with several foreign body-type MGCs. (B), granuloma with Langhans-type MGC (C), cathepsin K-deficient mice had significantly higher number of MGCs per lung section, $\left({ }^{*}-\mathrm{p}<0.05\right.$ when compared to Apoe-/- mice). (D), Mac-3 positive cells in granuloma (green - Mac-3, blue - nuclei), (E), osteopontin-containing epitheloid and giant cells (red osteopontin, blue - nuclei), (F), merge of D and E. (G), percentage of granuloma area stained for Mac-3, osteopontin, CD4 and CD8. (H) The collagen-stained area was quantified using color threshold and calculated as percentage of granuloma area $*^{*}-p<0.05$ when compared to Apoe-/- mice). (A, D-F), scale bars $30 \mu \mathrm{m}$, (B), scale bar, $20 \mu \mathrm{m}$.

stained for osteopontin, whereas the macrophage marker Mac-3, was not expressed in giant cells (Figure 4D-F). Granuloma cell composition analyzed by immunohistochemical staining did not reveal significant differences in the amount of $\mathrm{CD}^{+}$and $\mathrm{CD} 8^{+} \mathrm{T}$ cells as well as Mac-3 (macrophage marker) and osteopontin positive cells (epithelioid cells marker) in Apoe-/-Ctsk-/- mice when compared to their cathepsin K-expressing littermates (Figure 4G and [6]). The collagen content was significantly higher in granulomas of mice lacking cathepsin $\mathrm{K}$ (Figure 4H).

\section{Cathepsins $\mathrm{K}$ and $\mathrm{L}$ deficiencies and cathepsin $\mathrm{S}$ inhibition decreases the number and size of lung granulomas}

Apoe-/- mice lacking cathepsin $\mathrm{K}$ have shown a higher incidence of lung granulomas compared to Apoe-/- mice (table 1), but the size of granulomas was significantly smaller (Figure 5A, B, D). Cathepsin L deficiency resulted in the lower incidence and smaller size of granulomas (table 1 and Figure 5C, D). The number of granulomas decreased dramatically from an average of 34 per lung section in Apoe-/- mice to one in Apoe-/Ctsl-/- mice (Figure 5E). After 8 weeks of HFD the size of granulomas in Apoe-/- mice was smaller compared to 16 weeks of diet $\left(12.6 \pm 3.66 \mathrm{~mm}^{2}\right.$ vs. $\left.20.8 \pm 4.3\right)$ but granulomas were still well-formed (Figure $5 \mathrm{~F}$ ) and similarly to 16 weeks, they were present in $41 \%$ of mice (table 1). In cathepsin $S$ inhibitor-treated mice only individual epithelioid cells without well-formed granulomas were observed (Figure 5G) and epithelioid cells were present in $30 \%$ of mouse lungs. After one week of dosing, morning blood levels of active inhibitor reached $1.0 \pm 0.16 \mu \mathrm{M}$ ( $\mathrm{n}=6$ animals). This concentration likely approximates the peak blood level as mice feed predominantly at night. Cathepsin $S$ is highly expressed in the spleen and antigen-presenting cells and its inhibition impairs antigen presentation and causes a build-up of intermediate invariant chain (Ii) breakdown products $[29,30]$. Previously, we reported significant accumulation 

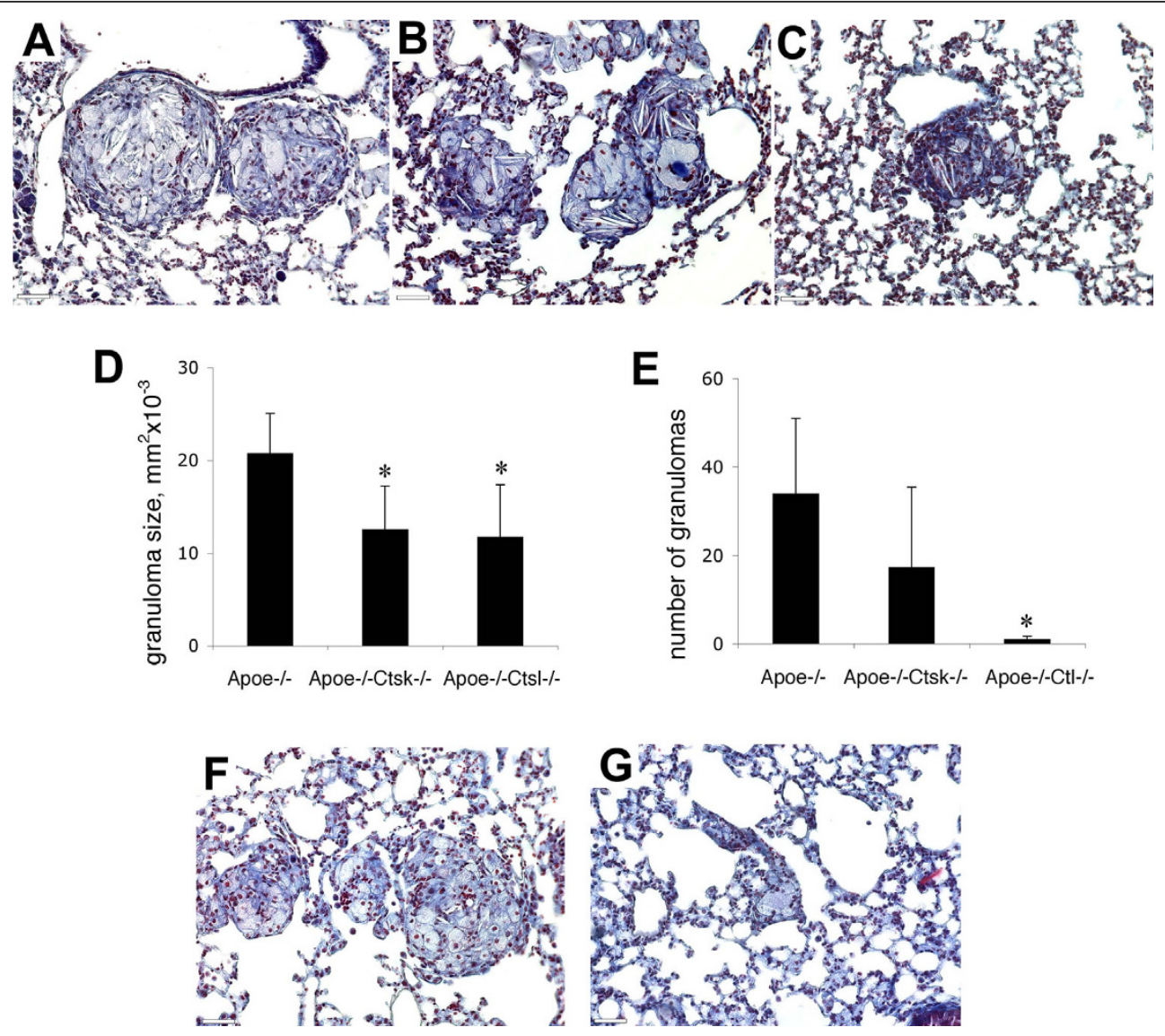

Figure 5 Changes in granuloma size and numbers. Granulomas in Apoe-/- (A), Apoe-/-Ctsk-/- (B) and Apoe-/-Cts/-/- mice after 16 weeks on HFD (C). (D), size of granulomas was significantly smaller in cathepsin K- and L-deficient mice. (E), number of granulomas in cathepsin L-deficient mice was dramatically decreased. (F), granulomas in Apoe-/- mice after 8 weeks on HFD. (G), Apoe-/- mice treated with cathepsin S inhibitor developed only individual epithelioid cells after 8 weeks on HFD. (A-C, F, G), trichrome stained sections, scale bars $65 \mu \mathrm{m} .{ }^{*}-\mathrm{p}<0.05$ when compared to Apoe-/- mice.

of $10 \mathrm{kDa}$ products of Ii degradation in cathepsin $\mathrm{S}$ inhibitor-treated mice after 8 weeks of HFD that provides an evidence of an efficient inhibition of cathepsin S [31].

\section{Effect of cathepsins on thymus hypertrophy}

In addition to fibrosis and granulomatous inflammation in lung, HFD induces fibrotic changes and hypertrophy in the thymus. Previously, we observed that after 16 weeks on HFD, Apoe-/- mice had more than a 3 -fold increase in thymus weight compared to their littermates on normal diet [6]. Cathepsin $\mathrm{K}$ and $\mathrm{L}$ deficiencies and cathepsin $\mathrm{S}$ inhibition did not prevent the development of fibrotic changes in thymi. In all mice, an accumulation of collagen fibers and the presence of MGCs were observed (Figure 6A-C). But the thymus hypertrophy was dependent on cathepsin activities: mice receiving the cathepsin S inhibitor, or lacking cathepsin K, have shown insignificantly lower weights of thymi, whereas in Apoe-/- Ctsl-/- mice thymi had more than 5 times smaller weights when compared to Apoe-/- mice (Figure 6D, F). As cathepsin L-deficient mice had a lower total body weight, a ratio between thymus and total body weight was evaluated. This proportion was significantly lower in cathepsin K-null mice and more than 4-times smaller in cathepsin L-deficient mice (Figure 6E).

Accumulation of CD4-positive cells in lungs is affected by cathepsin S inhibitor and cathepsin L deficiency

The formation of lung granulomas was accompanied by a more than 5-fold increase in the number of CD4positive cells in lungs of mice on HFD when compared to mice on normal diet (Figure 7A, B). Cathepsin K deficiency did not affect the CD4 population when compared to Apoe-/- mice. In contrast, disruption of cathepsin $\mathrm{L}$ and $\mathrm{S}$ activities resulted in an $18 \%$ and $43 \%$ lower accumulation of CD4-positive cells in lungs (Figure 7B, C).

\section{Discussion}

The formation of lung granulomas results in an extensive extracellular matrix remodeling. Collagen and elastin are the major components of the pulmonary matrix 

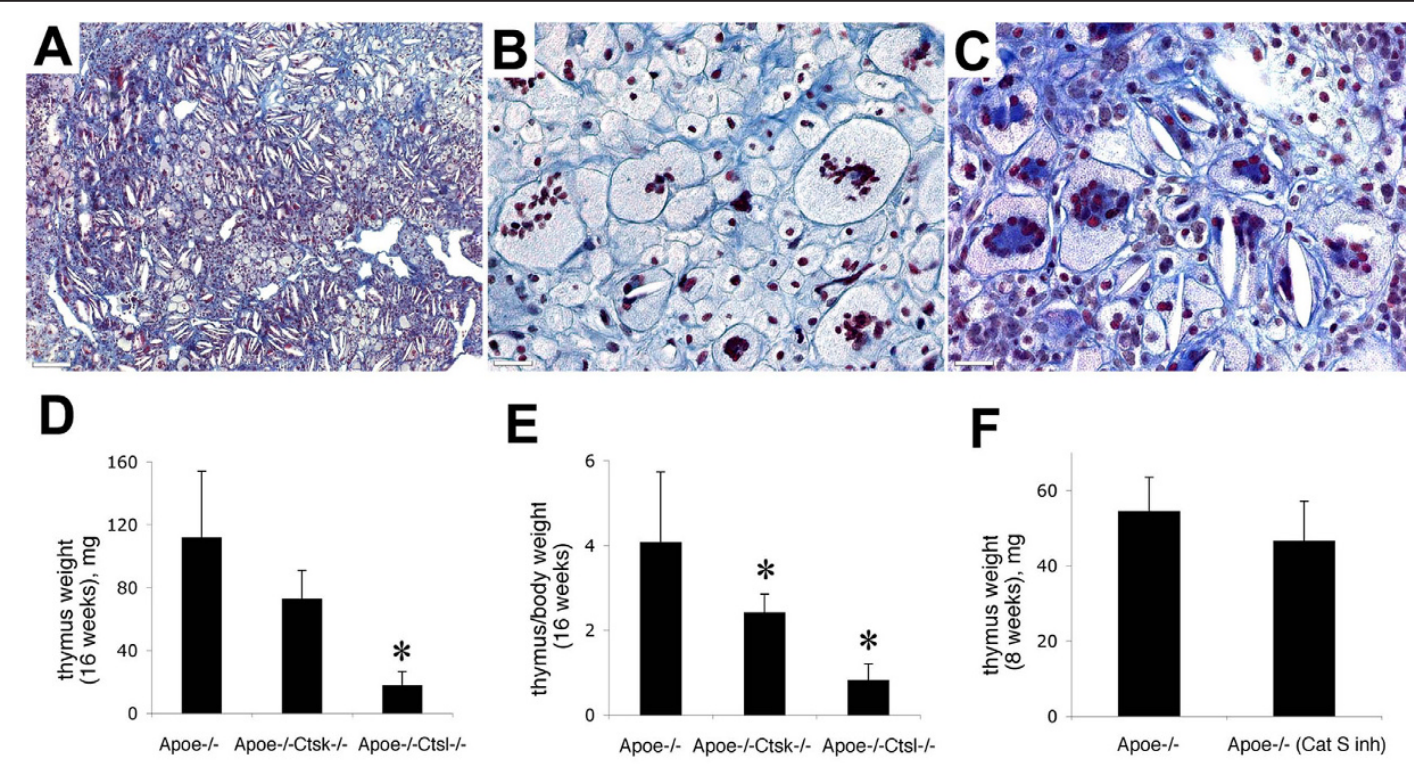

Figure 6 Fibrosis and MGCs in thymus. (A), fibrotic thymus in Apoe-/-Ctsl-/- mice. (B), foreign body type MGCs with random distribution of nuclei in Apoe-/-Ctsk-/- mice. (C), Langhans-type MGCs with horseshoe-like arrangement of nuclei in cathepsin $\mathrm{S}$ inhibitor treated mice. (D), cathepsin $L$ deficiency prevents hypertrophy of thymus. (E), proportion of thymus to total body weight was significantly lower in cathepsin Kand L-deficient mice. $(F)$, cathepsin $S$ inhibitor treatment did not prevent thymus hypertrophy. ${ }^{*}-p<0.05$ when compared to Apoe-/- mice. A-C, trichrome staining. (A), scale bar $130 \mu \mathrm{m},(\mathrm{B}, \mathrm{C})$, scale bars $30 \mu \mathrm{m}$.

and it is believed that a cooperative action of multiple enzymes is required for its turnover. Cathepsin $\mathrm{K}$ has a unique ability to cleave highly efficiently triple helical collagen at multiple sites and to act as a potent elastase as well [32]. Its strong expression in lung granulomas suggested an important role in granuloma formation and resolution, and indeed, lungs of Apoe-/-Ctsk-/mice showed significant differences in granuloma appearance, size, and composition. The increased incidence of lung granulomas in cathepsin K-deficient mice ( $88 \%$ vs. $41 \%$ ) correlates with the increased collagen fibers deposition ( $10 \%$ vs $20 \%$ ) that may consequently result in a delayed granuloma resolution. Lung granuloma formation and their spontaneous resolution as commonly observed in patients with sarcoidosis [33] require remodeling of the extracellular matrix. It is tempting to speculate that the increased amount of collagen in granulomas (Figure $4 \mathrm{H}$ ) and the presence of abundant collagen fibers between epithelioid cells in areas without well-formed granulomas (Figure 3F, G) in Ctsk-/- mice is due to the lack of the collagenase activity of cathepsin $\mathrm{K}$. This accumulation of collagen fibers might also be responsible for the smaller number and size of granulomas. In our measurements, accumulations of epithelioid cells were considered as granulomas only when they were present as well-formed and ball-shaped structures that are characteristic for sarcoidosis. In Apoe-/-Ctsk-/- mice, epithelioid cells were often
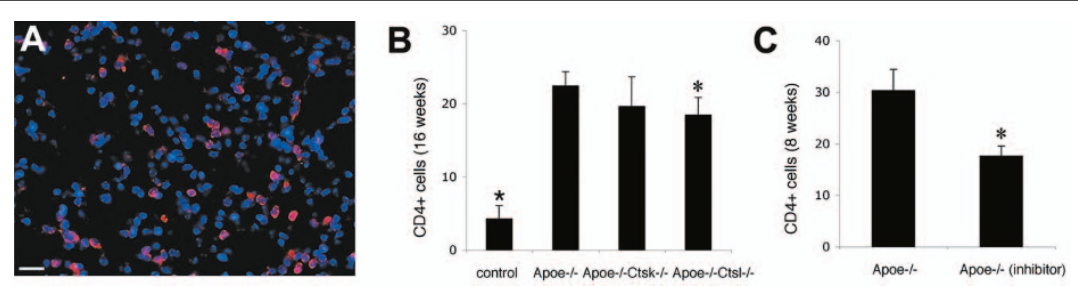

Figure 7 Effect of cathepsins on the amount of CD4-positive cells in lungs. The number of CD4-positive cells (A) was more than a 5-times higher in lungs of Apoe-/- mice as a result of HFD-feeding (B). Apoe-/- Ctsk-/- mice did not reveal a significant difference in its CD4 population, whereas Apoe-/- Ctsl-/- mice showed less dramatic accumulation of CD4 ${ }^{+}$cells when compared to Apoe-/- mice $(*-p<0.05$ between Apoe-/mice on HFD and Apoe-/- mice on normal diet; ${ }^{*}-p<0.05$ when compared to Apoe-/- mice on HFD). Cathepsin $\mathrm{S}$ inhibitor treatment resulted in a significant reduction of $\mathrm{CD}^{+}$cells in lungs of mice on HFD ( $C{ }^{*}-p<0.05$ when compared to mice on HFD without inhibitor). (A), Scale bar $30 \mu \mathrm{m}$. 
observed forming ring-like structures with dispersed collagen fibers, or were randomly distributed in fibrotic areas (Figure 3D, H).

The cell composition of granulomas in cathepsin $\mathrm{K}$-deficient mice was also changed. They contained a significantly higher number of MGCs. This type of cells is formed by the fusion of cells from the monocytemacrophage lineage [34]. In atherosclerotic plaques from Apoe-/-Ctsk-/- mice, macrophages have an increased size [35] and microarray analyses have revealed the upregulation of several macrophage genes, including CD36 [36]. Since CD36 participates in macrophage fusion [37], we suggest that it might be responsible for the increased number of MGCs in cathepsin K-deficient mice. The disruption of cathepsins $\mathrm{L}$ and $\mathrm{S}$ activities resulted in a more significant effect on granuloma formation. Cathepsin L deficiency reduced the size and the number of lung granulomas whereas mice treated with the cathepsin S inhibitor did not develop wellformed granulomas.

Analysis of available literature data suggests that the preventive effect of cathepsin L deficiency or cathepsin $\mathrm{S}$ inhibition on lung granuloma development may not only depend on their extracellular matrix-degrading activities, but on their involvement in antigen presentation as well $[17,38]$. Cathepsin S is expressed in B cells, macrophages, and dendritic cells and is required for invariant chain (li) degradation and antigen processing [30]. Cathepsin S-deficient mice have decreased MHC class II presentation in $\mathrm{B}$ and dendritic cells, and a reduced number of $\mathrm{CD} 4^{+} \mathrm{T}$-cells [15]. On the other hand, cathepsin $\mathrm{L}$ is expressed in cortical thymic epithelial cells and macrophages and is responsible for li degradation in $\mathrm{CD}_{4}^{+} \mathrm{T}$ cell selection in the thymus [17]. Cathepsin L-deficient mice have a reduction in their numbers of $\mathrm{CD}_{4}^{+}$cells in thymus and peripheral organs [39]. The roles of cathepsins $S$ and $L$ on the functions of $\mathrm{CD}_{4}^{+}$may have a direct influence on sarcoidosis development. $T$ cell activation is mandatory for the development of granulomatous reactions and $\mathrm{CD} 4^{+} \mathrm{T}$ cells of the Th1-type are essential for the formation and the maintenance of granulomas [18-21]. The decreased amount of $\mathrm{CD} 4^{+}$cells in lungs of mice lacking cathepsin $\mathrm{L}$ or treated with cathepsin S inhibitor (Figure 7B, C) supports the suggestion that the effect of these two cathepsins on the granuloma formation is related to their role in antigen presentation and T-cell selection.

In addition to its involvement in antigen presentation, cathepsin L has been described to play a role in $\mathrm{T}$-cell actin polymerization, shape polarization, chemotaxis. Cathepsin L deficiency significantly decreases the expression of laminin, fibronectin, and collagens I and II in thymus of cathepsin L-deficient mice [40]. This might partially explain why Apoe-/- Ctsl-/- mice had significantly smaller thymi compared to Apoe-/- mice (Figure 7D, E).

In conclusion, our results show that the disruption of cathepsin $\mathrm{L}$ and $\mathrm{S}$ activities prevents the development of lung granulomas, whereas cathepsin $\mathrm{K}$ deficiency results in altered granuloma composition in mice. These results suggest that interventions in cathepsin $\mathrm{S}$ and $\mathrm{L}$ activities may yield a therapeutic benefit for patients with sarcoidosis, i.e., a potential prevention of disease progression. Such an approach, however, would require extreme caution as both cathepsins have been described as critical participants in antigen presentation and their inhibition may result in increased infection and cancer rates.

\section{Acknowledgements}

The authors gratefully acknowledge Drs. Paul Saftig (University of Kiel, Germany) and Christoph Peters (University of Freiburg, Germany) for providing the mouse strains for cathepsin $\mathrm{K}$ and $\mathrm{L}$-deficiencies. We also gratefully acknowledge Stephanie Alleyn, Aleksandar Popovic, Simon Wong, Denis Normandin and Réné St-Jacques from Merck-Frosst for their excellent technical assistance and assistance with animal care during this study. This work was supported by the CIHR grant C04-0435 and a Canada Research Chair Award (D. B.).

\section{Statement of Authors' contributions}

AOS designed and carried out experiments, analysed data and wrote the paper, JYG carried out experiments with cathepsin S inhibitor, MDP designed and carried out experiments with cathepsin S inhibitor and wrote inhibitor-related sections of the paper, DB conceived experiments, analysed data and wrote the paper. All authors have approved the final manuscript.

\section{Declaration of competing interests}

The authors declare that they have no competing interests.

\section{Author details}

'Department of Oral Biological and Medical Sciences, Faculty of Dentistry, University of British Columbia, Vancouver, BC, Canada. ${ }^{2}$ Merck Frosst Center for Therapeutic Research, Kirkland, QC, Canada.

Received: 9 September 2010 Accepted: 20 January 2011

Published: 20 January 2011

\section{References}

1. Wolters PJ, Chapman HA: Importance of lysosomal cysteine proteases in lung disease. Respir Res 2000, 1(3):170-177.

2. Buhling F, Waldburg N, Reisenauer A, Heimburg A, Golpon H, Welte T: Lysosomal cysteine proteases in the lung: role in protein processing and immunoregulation. Eur Respir J 2004, 23(4):620-628.

3. Hirakawa H, Pierce RA, Bingol-Karakoc G, Karaaslan C, Weng M, Shi GP, Saad A, Weber E, Mariani TJ, Starcher B, et al: Cathepsin S deficiency confers protection from neonatal hyperoxia-induced lung injury. Am J Respir Crit Care Med 2007, 176(8):778-785.

4. Williams AS, Eynott PR, Leung SY, Nath P, Jupp R, De Sanctis GT, Resnick R, Adcock IM, Chung KF: Role of cathepsin S in ozone-induced airway hyperresponsiveness and inflammation. Pulm Pharmacol Ther 2009, 22(1):27-32

5. Veillard F, Lecaille F, Lalmanach G: Lung cysteine cathepsins: intruders or unorthodox contributors to the kallikrein-kinin system? Int J Biochem Cell Biol 2008, 40(6-7):1079-1094.

6. Samokhin AO, Buhling F, Theissig F, Bromme D: ApoE-deficient mice on cholate-containing high-fat diet reveal a pathology similar to lung sarcoidosis. Am J Pathol 2010, 176(3):1148-1156.

7. Lynch JP, Ma YL, Koss MN, White ES: Pulmonary sarcoidosis. Semin Respir Crit Care Med 2007, 28(1):53-74.

8. Sharma OP: Sarcoidosis: a historical perspective. Clin Dermatol 2007, 25(3):232-241. 
9. Lalmanach G, Diot E, Godat E, Lecaille F, Herve-Grepinet V: Cysteine cathepsins and caspases in silicosis. Biol Chem 2006, 387(7):863-870

10. Diaz A, Willis AC, Sim RB: Expression of the proteinase specialized in bone resorption, cathepsin $\mathrm{K}$, in granulomatous inflammation. Mol Med 2000, 6(8):648-659.

11. Buhling F, Reisenauer A, Gerber A, Kruger S, Weber E, Bromme D, Roessner A, Ansorge S, Welte T, Rocken C: Cathepsin K-a marker of macrophage differentiation? J Pathol 2001, 195(3):375-382

12. Chilosi AM, Brizzolara D, Lami L, Pizzoli C, Gasperini F, Pecini C, Cipriani P, Zoccolotti P: Reading and Spelling Disabilities in Children With and Without a History of Early Language Delay: A Neuropsychological and Linguistic Study. Child Neuropsychol 2009, 1-23.

13. Serveau-Avesque C, Martino MF, Herve-Grepinet V, Hazouard E, Gauthier F, Diot $\mathrm{E}$, Lalmanach $\mathrm{G}$ : Active cathepsins $\mathrm{B}, \mathrm{H}, \mathrm{K}, \mathrm{L}$ and $\mathrm{S}$ in human inflammatory bronchoalveolar lavage fluids. Biol Cell 2006, 98(1):15-22.

14. Shi GP, Munger JS, Meara JP, Rich DH, Chapman HA: Molecular cloning and expression of human alveolar macrophage cathepsin $\mathrm{S}$, an elastinolytic cysteine protease. J Biol Chem 1992, 267:7258-7262.

15. Honey K, Rudensky AY: Lysosomal cysteine proteases regulate antigen presentation. Nat Rev Immunol 2003, 3(6):472-482.

16. Hsing LC, Rudensky AY: The lysosomal cysteine proteases in MHC class II antigen presentation. Immunol Rev 2005, 207:229-241.

17. Nakagawa T, Roth W, Wong P, Nelson A, Farr A, Deussing J, Villadangos JA, Ploegh H, Peters C, Rudensky AY: Cathepsin L: critical role in li degradation and CD4 T cell selection in the thymus. Science 1998, 280:450-453.

18. Grunewald J, Eklund A: Role of CD4+ T cells in sarcoidosis. Proc Am Thorac Soc 2007, 4(5):461-464.

19. Zissel G, Prasse A, Muller-Quernheim J: Sarcoidosis-immunopathogenetic concepts. Semin Respir Crit Care Med 2007, 28(1):3-14.

20. Gerke AK, Hunninghake G: The immunology of sarcoidosis. Clin Chest Med 2008, 29(3):379-390, vii.

21. Noor A, Knox KS: Immunopathogenesis of sarcoidosis. Clin Dermatol 2007, 25(3):250-258.

22. Samokhin AO, Wong A, Saftig P, Bromme D: Role of cathepsin K in structural changes in brachiocephalic artery during progression of atherosclerosis in apoE-deficient mice. Atherosclerosis 2008, 200(1):58-68.

23. Saftig $P$, Wehmeyer $O$, Hunziker $E$, Jones S, Boyde A, Rommerskirch W, von Figura K: Impaired osteoclastic bone resorption leads to osteopetrosis in cathepsin K-deficient mice. Proc Natl Acad Sci USA 1998, 95:13453-13458.

24. Buhling F, Rocken C, Brasch F, Hartig R, Yasuda Y, Saftig P, Bromme D, Welte T: Pivotal role of cathepsin K in lung fibrosis. Am J Pathol 2004, 164(6):2203-2216

25. Roth W, Deussing J, Botchkarev VA, Pauly-Evers M, Saftig P, Hafner A, Schmidt P, Schmahl W, Scherer J, Anton-Lamprecht I, et al: Cathepsin L deficiency as molecular defect of furless: hyperproliferation of keratinocytes and pertubation of hair follicle cycling. Faseb J 2000 , 14(13):2075-2086.

26. Gauthier JY, Black WC, Courchesne I, Cromlish W, Desmarais S, Houle R, Lamontagne S, Li CS, Masse F, McKay DJ, et al: The identification of potent, selective, and bioavailable cathepsin S inhibitors. Bioorg Med Chem Lett 2007, 17(17):4929-4933.

27. Xia L, Kilb J, Wex H, Lipyansky A, Breuil V, Stein L, Palmer JT, Dempster DW, Brömme D: Localization of rat cathepsin $\mathrm{K}$ in osteoclasts and resorption pits: Inhibition of bone resorption cathepsin K-activity by peptidyl vinyl sulfones. Biol Chem 1999, 380:679-687.

28. Kocks JR, Davalos-Misslitz AC, Hintzen G, Ohl L, Forster R: Regulatory T cells interfere with the development of bronchus-associated lymphoid tissue. J Exp Med 2007, 204(4):723-734.

29. Riese RJ, Wolf $P$, Bromme D, Natkin LR, Villadangos JA, Ploegh HL, Chapman HA: Essential role for cathepsin S in MHC class II-associated invariant chain processing and peptide loading. Immunity 1996, 4(4):357-366.

30. Riese RJ, Mitchell RN, Villadangos JA, Shi GP, Palmer JT, Karp ER, De Sanctis GT, Ploegh HL, Chapman HA: Cathepsin S activity regulates antigen presentation and immunity. J Clin Invest 1998, 101(11):2351-2363.

31. Samokhin AO, Wilson S, Nho B, Lizame ML, Musenden OE, Bromme D: Cholate-containing high-fat diet induces the formation of multinucleated giant cells in atherosclerotic plaques of apolipoprotein E-/- mice. Arterioscler Thromb Vasc Biol 2010, 30(6):1166-1173.
32. Brömme D, Okamoto K, Wang BB, Biroc S: Human cathepsin O2, a matrix protein-degrading cysteine protease expressed in osteoclasts. Functional expression of human cathepsin $\mathrm{O} 2$ in Spodoptera frugiperda and characterization of the enzyme. J Biol Chem 1996, 271(4):2126-2132.

33. Nagai $S$, Handa $T$, Ito $Y$, Ohta $K$, Tamaya M, Izumi T: Outcome of sarcoidosis. Clin Chest Med 2008, 29(3):565-574, X.

34. van Maarsseveen TC, Vos W, van Diest PJ: Giant cell formation in sarcoidosis: cell fusion or proliferation with non-division? Clin Exp Immunol 2009, 155(3):476-486.

35. Lutgens E, Lutgens SP, Faber BC, Heeneman S, Gijbels MM, de Winther MP, Frederik P, van der Made I, Daugherty A, Sijbers AM, et al: Disruption of the cathepsin $\mathrm{K}$ gene reduces atherosclerosis progression and induces plaque fibrosis but accelerates macrophage foam cell formation. Circulation 2006, 113(1):98-107.

36. Lutgens SP, Kisters N, Lutgens E, van Haaften RI, Evelo $C T$, de Winther MP, Saftig P, Daemen MJ, Heeneman S, Cleutjens KB: Gene profiling of cathepsin $\mathrm{K}$ deficiency in atherogenesis: profibrotic but lipogenic. J Pathol 2006, 210(3):334-343.

37. Helming L, Winter J, Gordon S: The scavenger receptor CD36 plays a role in cytokine-induced macrophage fusion. J Cell Sci 2009, 122(Pt 4):453-459.

38. Nakagawa TY, Brissette WH, Lira PD, Griffiths RJ, Petrushova N, Stock J, McNeish JD, Eastman SE, Howard ED, Clarke SR, et al: Impaired invariant chain degradation and antigen presentation and diminished collageninduced arthritis in cathepsin S null mice. Immunity 1999, 10:207-217.

39. Honey K, Nakagawa T, Peters C, Rudensky A: Cathepsin L regulates CD4+ $T$ cell selection independently of its effect on invariant chain: a role in the generation of positively selecting peptide ligands. J Exp Med 2002, 195(10):1349-1358

40. Lombardi G, Burzyn D, Mundinano J, Berguer P, Bekinschtein P, Costa $H$, Castillo LF, Goldman A, Meiss R, Piazzon I, et al: Cathepsin-L influences the expression of extracellular matrix in lymphoid organs and plays a role in the regulation of thymic output and of peripheral $\mathrm{T}$ cell number. $\mathrm{J}$ Immunol 2005, 174(11):7022-7032.

doi:10.1186/1465-9921-12-13

Cite this article as: Samokhin et al.: Lack of cathepsin activities alter or prevent the development of lung granulomas in a mouse model of sarcoidosis. Respiratory Research 2011 12:13.

\section{Submit your next manuscript to BioMed Central and take full advantage of:}

- Convenient online submission

- Thorough peer review

- No space constraints or color figure charges

- Immediate publication on acceptance

- Inclusion in PubMed, CAS, Scopus and Google Scholar

- Research which is freely available for redistribution

Submit your manuscript at www.biomedcentral.com/submit
C) Biomed Central 